Article

\title{
Prognostic Factors Associated with Recovery from Recurrent Idiopathic Sudden Sensorineural Hearing Loss: Retrospective Analysis and Systematic Review
}

\author{
So Young Jeon, Dae Woong Kang (D), Sang Hoon Kim (D), Jae Yong Byun and Seung Geun Yeo * (D) \\ Department of Otorhinolaryngology-Head \& Neck Surgery, School of Medicine, Kyung Hee University, \\ 23 Kyungheedae-ro, Dongdaemun-gu, Seoul 02447, Korea; iamjsy89@gmail.com (S.Y.J.); \\ kkang814@naver.com (D.W.K.); hoon0700@naver.com (S.H.K.); otorhioo512@naver.com (J.Y.B.) \\ * Correspondence: yeo2park@gmail.com; Tel.: +82-2-958-8980; Fax: +82-2-958-8470
}

check for updates

Citation: Jeon, S.Y.; Kang, D.W.; Kim, S.H.; Byun, J.Y.; Yeo, S.G. Prognostic Factors Associated with Recovery from Recurrent Idiopathic Sudden Sensorineural Hearing Loss:

Retrospective Analysis and

Systematic Review. J. Clin. Med. 2022, 11, 1453. https://doi.org/10.3390/ jcm11051453

Academic Editor: George Psillas

Received: 4 February 2022

Accepted: 5 March 2022

Published: 7 March 2022

Publisher's Note: MDPI stays neutral with regard to jurisdictional claims in published maps and institutional affiliations.

Copyright: (C) 2022 by the authors. Licensee MDPI, Basel, Switzerland. This article is an open access article distributed under the terms and conditions of the Creative Commons Attribution (CC BY) license (https:// creativecommons.org/licenses/by/ $4.0 /)$.

\begin{abstract}
Although idiopathic sudden sensorineural hearing loss (ISSNHL) is uncommon, recurrent ISSNHL is even rarer. The knowledge about factors associated with patient recovery from recurrent episodes is needed to counsel and treat the patients. Medical records of patients admitted for high dose oral steroid therapy for recurrent ISSNHL between January 2009 and December 2021 were reviewed. Their demographic and clinical characteristics, co-morbid symptoms, and audiologic results were analyzed. The 38 patients admitted for treatment of recurrent ISSNHL included 14 men and 24 women. Recovery rates after the first and recurrent episodes of ISSNHL were $78.9 \%$ and $63.2 \%$, respectively. Patients who recovered after recurrent episodes showed significantly higher rates of ear fullness symptoms and early treatment onset than those who did not recover $(p<0.05$ each). Of the 30 patients who recovered after the first episode, those who had ear fullness symptoms $(p<0.05$, odds ratio (OR) $0.1,95 \%$ confidence interval (CI) 0.01-0.76) and who showed a lower initial hearing threshold ( $p<0.05$, OR 1.06, 95\% CI 1.01-1.12) during the recurrent episode showed significantly better or similar recovery than after the first episode. Ear fullness symptoms and less initial hearing loss were associated with a more favorable prognosis after intial than after recurrent ISSNHL.
\end{abstract}

Keywords: sudden; idiopathic sensorineural hearing loss; recurrent

\section{Introduction}

Idiopathic sudden sensorineural hearing loss (ISSNHL) is typically defined as a sensorineural hearing loss greater than $30 \mathrm{~dB}$ over at least three consecutive frequencies within three days [1]. Its incidence is 5 to 20 per 100,000 people per year [2]. Studies analyzing long-term outcomes of ISSNHL have found that recurrence rates vary widely, ranging between $0.8 \%$ and $47 \%$ [3-8].

There is no known single cause of ISSNHL, but factors may include viral infection, vascular disturbance, cochlear membrane rupture, immune-mediated mechanisms, tumor, autonomic nervous disease, ototoxic drugs, and congenital anomaly, or it may be idiopathic [9]. Although many studies have assessed the causes, pathogenesis, diagnostic criteria, treatment, and prognostic factors of ISSNHL [10-12], few have analyzed the clinical features and prognostic factors associated with recurrent ISSNHL. Furthermore, to our knowledge, no study has compared the clinical features or factors associated with recovery from initial and recurrent episodes of ISSNHL. This study retrospectively analyzed 38 patients with recurrent ISSNHL and compared the clinical features and prognostic factors associated with recovery from initial and recurrent episodes of ISSNHL. 


\section{Subjects and Methods}

\subsection{Study Design}

This retrospective study included patients with recurrent ISSNHL who visited the ear, nose, and throat (ENT) clinic at Kyung-Hee Medical Center and Gang-dong Kyung-Hee Medical Center for SSNHL and were admitted for high dose steroid therapy between January 2009 and December 2021. Patients were excluded if they had vertigo, chronic otitis media, a history of middle ear cavity surgery, disorders of the central nervous system, tumors, or progressive sensorineural hearing loss.

The medical records of the patients were reviewed, and their demographic and clinical characteristics were recorded, including age, sex, body mass index, medical history, comorbid symptoms, days from onset to treatment, time to recovery, and duration of recurrence. Only current alcohol use and smoking were considered, respectively. Following admission, all patients underwent daily pure tone audiometry (PTA) tests in a sound-treated audiology booth in the ENT clinic by qualified and experienced audiologists, with hearing thresholds calculated using the six-division method $((500 \mathrm{~Hz}+(1000 \mathrm{~Hz} \times 2)+(2000 \mathrm{~Hz} \times 2)+$ $4000 \mathrm{~Hz}) / 6$ ).

High dose steroid therapy consisted of $1 \mathrm{mg} / \mathrm{kg} /$ day oral methylprednisolone for four days, followed by tapering. Patients were discharged after tapering and followed in the outpatient clinic. Hearing threshold at recovery was defined as the threshold observed when PTA tests showed no improvement for two weeks. Hearing recovery was assessed using Siegel's classification [13], with patients categorized as experiencing complete, partial, slight, and no recovery for both episodes of ISSNHL. Complete, partial, and slight recovery were grouped as the recovery group. Factors were compared in patients who did and did not recover after both episodes (Table 1). To analyze factors associated with poorer outcomes after the recurrent than after the first episode of ISSNHL, patients who recovered after the first episode were divided into those who experienced similar or better recovery and those who experienced poorer recovery after the recurrent than after the first episode. In this analysis, patients who did not recover after the first episode were excluded (Table 2).

Table 1. Characteristics of patients who did and not recover after the first and recurrent episodes of idiopathic sudden sensorineural hearing loss.

\begin{tabular}{|c|c|c|c|c|c|c|}
\hline \multirow{3}{*}{ Variables } & \multicolumn{3}{|c|}{ First Episode } & \multicolumn{3}{|c|}{ Recurrent Episode } \\
\hline & $\begin{array}{l}\text { Recovery } \\
(n=30)\end{array}$ & $\begin{array}{l}\text { No Recovery } \\
\quad(n=8)\end{array}$ & \multirow{2}{*}{$p$-Value } & $\begin{array}{l}\text { Recovery } \\
(n=24)\end{array}$ & $\begin{array}{l}\text { No Recovery } \\
\quad(n=14)\end{array}$ & \multirow{2}{*}{$p$-Value } \\
\hline & $\begin{array}{c}n(\%) \text { or } \\
\text { Mean } \pm \text { SD }\end{array}$ & $\begin{array}{c}n(\%) \text { or } \\
\text { Mean } \pm \text { SD }\end{array}$ & & $\begin{array}{c}n(\%) \text { or } \\
\text { Mean } \pm \text { SD }\end{array}$ & $\begin{array}{c}n(\%) \text { or } \\
\text { Mean } \pm \text { SD }\end{array}$ & \\
\hline Age (year) mean \pm SD & $48.90 \pm 16.40$ & $48.75 \pm 18.11$ & 0.7489 & $53.63 \pm 14.13$ & $51.00 \pm 19.52$ & 0.9880 \\
\hline \multirow{2}{*}{ Sex Female } & $12(40.00 \%)$ & $2(25.00 \%)$ & 0.6836 & $8(3.33 \%)$ & $6(42.86 \%)$ & 0.7293 \\
\hline & $18(60.00 \%)$ & $6(75.00 \%)$ & & $16(66.67 \%)$ & $8(57.14 \%)$ & \\
\hline $\mathrm{BMI}\left(\mathrm{kg} / \mathrm{m}^{2}\right)$, mean $\pm \mathrm{SD}$ & $22.89 \pm 2.57$ & $22.42 \pm 2.78$ & 0.6605 & $22.78 \pm 2.75$ & $22.80 \pm 2.37$ & 0.8373 \\
\hline Alcohol & $4(13.33 \%)$ & $3(37.50 \%)$ & 0.1461 & $5(20.83 \%)$ & $2(14.29 \%)$ & 1.0000 \\
\hline Smoking & $8(26.67 \%)$ & $2(25.00 \%)$ & 1.0000 & $5(20.83 \%)$ & $5(35.71 \%)$ & 0.4485 \\
\hline HTN & $5(16.67 \%)$ & $2(25.00 \%)$ & 0.6236 & $3(12.50 \%)$ & $4(28.57 \%)$ & 0.3870 \\
\hline DM & $7(23.33 \%)$ & $1(12.50 \%)$ & 0.6600 & $6(25.00 \%)$ & $2(14.29 \%)$ & 0.6836 \\
\hline Tinnitus & $19(63.33 \%)$ & $6(75.00 \%)$ & 0.6893 & $16(66.67 \%)$ & $12(85.71 \%)$ & 0.2685 \\
\hline Ear fullness & $20(66.67 \%)$ & $8(100.00 \%)$ & 0.0821 & $22(91.67 \%)$ & $4(28.57 \%)$ & $0.0001 *$ \\
\hline Treatment onset (days), mean \pm SD & $7.17 \pm 16.07$ & $5.50 \pm 5.01$ & 0.5193 & $5.58 \pm 11.99$ & $16.71 \pm 20.73$ & $0.0361 *$ \\
\hline Recovery time (months), mean $\pm \mathrm{SD}$ & $0.95 \pm 1.04$ & $4.57 \pm 10.29$ & 0.2630 & $1.31 \pm 2.04$ & $3.01 \pm 5.07$ & 0.0303 * \\
\hline $\begin{array}{l}\text { Hearing level of the affected ear } \\
\text { before treatment }(\mathrm{dB}) \text {, mean } \pm \mathrm{SD}\end{array}$ & $48.44 \pm 25.45$ & $47.60 \pm 16.27$ & 0.8588 & $44.58 \pm 21.94$ & $49.17 \pm 11.92$ & 0.5686 \\
\hline $\begin{array}{l}\text { Hearing level of the affected ear after } \\
\text { treatment }(\mathrm{dB}), \text { mean } \pm \mathrm{SD}\end{array}$ & $21.00 \pm 14.87$ & $41.56 \pm 15.88$ & 0.0023 * & $23.13 \pm 13.60$ & $53.39 \pm 15.35$ & $<0.0001 *$ \\
\hline Time to recurrence (days), mean \pm SD & - & - & - & $43.22 \pm 54.31$ & $44.86 \pm 37.84$ & 0.3697 \\
\hline
\end{tabular}


Table 2. Distribution of patients according to types of recovery after the first and recurrent episodes of idiopathic sudden sensorineural hearing loss. Complete, partial, slight and no recovery were determined according to the Siegel's criteria [13].

\begin{tabular}{ccccccc}
\hline & & \multicolumn{3}{c}{ Recurrent Episode } \\
\cline { 2 - 7 } & $\begin{array}{c}\text { Recovery } \\
\text { Type }\end{array}$ & Complete & Partial & Slight & No & Total \\
\hline \multirow{3}{*}{ First } & Complete & 15 & 0 & 1 & 5 & 21 \\
episode & Partial & 1 & 2 & 2 & 3 & 8 \\
& Slight & 0 & 0 & 0 & 1 & 1 \\
& No & 2 & 1 & 0 & 5 & 8 \\
& Total & 18 & 3 & 3 & 14 & 38 \\
\hline
\end{tabular}

\subsection{Statistical Analysis}

Categorical variables were compared using Fisher's exact tests and continuous variables were compared using Wilcoxon rank sum tests. Factors associated with recovery were assessed by multiple ordinal logistic regression analysis, adjusted by age and sex. All statistical analyses were performed using the SAS9.4 (Statistical Analysis System version, SAS Institute, Cary, NC, USA) software, with a $p$-value $<0.05$ defined as statistically significant.

\subsection{Research on Recurrent ISSNHL}

This systematic review was performed in accordance with the Primary Reporting Items for Systematic Review and Meta-analyses (PRISMA) statement [14]. Studies were included if (a) they were retrospective or prospective investigative studies; (b) all patients had been diagnosed with recurrent idiopathic sudden sensorineural hearing loss, with those having other causes of hearing loss excluded; and (c) the studies were published in English Studies were excluded if they were (a) unpublished data; (b) review articles; (c) grey literature; (d) case reports; or (e) duplicates of published research. Studies published before 1 September 2021 were retrieved by one of the investigators (S.Y.J.) from three electronic databases: SCOPUS, PubMed and the Cochrane Library. Search terms included "recurrent sudden hearing loss".

\section{Results}

During the study period, 38 patients with recurrent ISSNHL were treated for recurrent ISSNHL; their demographic, audiometric, and other clinical characteristics are summarized in Table 1 . The 38 patients consisted of $14(36.8 \%)$ men and $24(63.2 \%)$ women. Their mean age at the first episode was 48.9 years (range 7-69 years), and their mean age at the recurrent episode was 52.7 years (range 12-76 years). Recurrences were ipsilateral in thirty-five $(92.1 \%)$ patients and contralateral in three $(7.9 \%)$. Thirty $(78.9 \%)$ patients recovered after the first episode, whereas eight $(21.1 \%)$ did not. In comparison, $24(63.2 \%)$ patients recovered after the recurrent episode, whereas 14 (36.8\%) did not.

A comparison of demographic and clinical characteristics of the patients who did and did not recover after the first episode showed no significant differences. In contrast, a comparison of patients who did and did not recover after the recurrent episode showed that the symptom of ear fullness $(91.7 \%$ vs. $28.6 \% ; p<0.05)$ was significantly more frequent, time to treatment onset significantly shorter (5.6 days vs. 16.7 days, $p<0.05)$ and recovery time significantly shorter $(1.3$ months vs. 3.1 months, $p<0.05)$ in patients who did rather than did not recover after the recurrent episode (Table 1).

Of the 30 patients who recovered after the first episode, 18 (60.0\%) showed better or similar recovery after the recurrent episode, whereas $12(40.0 \%)$ showed poorer recovery after the recurrent rather than after the first episode (Table 3). Ear fullness symptoms were significantly less frequent $(50 \%$ vs. $88.9 \%, p<0.05)$ and mean initial hearing threshold significantly higher $(57.2 \mathrm{~dB}$ vs. $40.1 \mathrm{~dB}, p<0.05)$ in patients who did rather than did not 
experience poorer recovery after the recurrent rather than after the first episode of ISSNHL (Table 3).

Table 3. Characteristics of patients who did and did not experience a poorer recovery after a recurrent episode than after the first episode of idiopathic sudden sensorineural hearing loss.

\begin{tabular}{|c|c|c|c|}
\hline \multirow[t]{2}{*}{ Variables } & $\begin{array}{l}\text { No Worse than } \\
\text { after the First } \\
\text { Episode }(n=18)\end{array}$ & $\begin{array}{c}\text { Worse than } \\
\text { after the First } \\
\text { Episode }(n=12)\end{array}$ & \multirow[t]{2}{*}{$p$-Value } \\
\hline & $\begin{array}{l}n(\%) \text { or Mean } \\
\quad \pm \text { SD }\end{array}$ & $\begin{array}{l}n(\%) \text { or Mean } \\
\quad \pm \text { SD }\end{array}$ & \\
\hline Age (year), mean \pm SD & $52.33 \pm 13.81$ & $53.00 \pm 20.78$ & 0.5855 \\
\hline Male & $7(38.89 \%)$ & $5(41.67 \%)$ & 1.0000 \\
\hline sex Female & $11(61.11 \%)$ & $7(58.33 \%)$ & \\
\hline $\mathrm{BMI}\left(\mathrm{kg} / \mathrm{m}^{2}\right)$, mean $\pm \mathrm{SD}$ & $22.70 \pm 2.71$ & $23.18 \pm 2.42$ & 0.3645 \\
\hline Alcohol & $3(16.67 \%)$ & $1(8.33 \%)$ & 0.6315 \\
\hline Smoking & $5(27.78 \%)$ & $3(25.00 \%)$ & 1.0000 \\
\hline HTN & $1(5.65 \%)$ & $4(33.33 \%)$ & 0.1282 \\
\hline $\mathrm{DM}$ & $4(22.22 \%)$ & $3(25.00 \%)$ & 1.0000 \\
\hline Tinnitus & $12(66.67 \%)$ & $10(83.33 \%)$ & 0.4192 \\
\hline Ear fullness & $16(88.89 \%)$ & $6(50.00 \%)$ & $0.0342 *$ \\
\hline Treatment onset (days), mean \pm SD & $5.67 \pm 13.69$ & $8.33 \pm 10.74$ & 0.1721 \\
\hline Recovery time (months), mean \pm SD & $1.26 \pm 2.25$ & $1.47 \pm 1.29$ & 0.0992 \\
\hline $\begin{array}{l}\text { Hearing level of the affected ear before } \\
\text { treatment }(\mathrm{dB}) \text {, mean } \pm \mathrm{SD}\end{array}$ & $40.05 \pm 20.17$ & $57.22 \pm 12.92$ & 0.0357 * \\
\hline $\begin{array}{l}\text { Hearing level of the affected ear after } \\
\text { treatment }(\mathrm{dB}), \text { mean } \pm S D\end{array}$ & $18.29 \pm 8.47$ & $52.36 \pm 12.08$ & $<0.0001$ * \\
\hline Time to recurrence (days), mean \pm SD & $34.65 \pm 37.54$ & $53.35 \pm 37.46$ & 0.1139 \\
\hline
\end{tabular}

Abbreviation SD; standard deviation, BMI; body mass index, HTN; hypertension, DM; diabetes mellitus. $* p<0.05$.

Based on the results of preliminary simple linear regression analysis to determine the factors associated with poorer recovery after the recurrent rather than after the first episode of ISSNHL, multiple regression analysis was performed with adjustment for age and sex (Table 4). Ear fullness symptoms at the time of ISSNHL recurrence were associated with a lower risk of poorer recovery after the recurrent episode $(p<0.05$, odds ratio (OR) $0.1,95 \%$ confidence interval (CI)] 0.01-0.76). Higher hearing loss at the time of ISSNHL recurrence was associated with a higher risk of poorer recovery after the recurrent episode $(p<0.05$, OR $1.06,95 \%$ CI 1.01-1.12).

Following ISSNHL recurrence, 23 patients underwent temporal bone MRI scans to rule out brain tumors or other ear abnormalities. None of these patients showed evidence of cerebellopontine angle tumors.

Using the search term "recurrent sudden hearing loss", 35 papers were identified from the three databases. Only nine $(25.7 \%)$ of these studies fulfilled the inclusion criteria and were reviewed and these are shown in Figure 1. The characteristics of the included studies are shown in Table 5. This review especially focused on recovery rate from recurrent ISSNHL, although two of these studies $[7,8]$ only provided data on the recurrence rate. The nine previous studies reported that the rate of recovery in patients with recurrent ISSNHL ranged from $43.4 \%$ to $78.6 \%$. Only one study reported the second recurrence rate, which was $21.4 \%$. In most studies, the proportion of females and males was almost the same. These studies utilized different tests, including electrocochleography (ECohG) and vestibular-evoked myogenic potential (VEMP), and analyzed different parameters, including neutrophil to lymphocyte ratio (NLR) and platelet to lymphocyte ratio (PLR), to identify prognostic factors associated with recurrent ISSNHL. 
Table 4. Adjusted risk factors for poorer recovery after a recurrent rather than after the first episode of ISSNHL.

\begin{tabular}{|c|c|c|c|c|c|c|}
\hline \multirow{2}{*}{ Variables } & \multicolumn{3}{|c|}{ Simple Logistic Model } & \multicolumn{3}{|c|}{ Multiple Logistic Model * } \\
\hline & OR & $95 \%$ CI & $p$-Value & OR & $95 \%$ CI & $p$-Value \\
\hline Age (year) & 1.00 & $0.96-1.05$ & 0.9128 & adj. & & \\
\hline Female (ref. Male) & 0.89 & $0.20-3.95$ & 0.8791 & adj. & & \\
\hline BMI & 1.08 & $0.80-1.45$ & 0.6213 & 1.01 & $0.69-1.47$ & 0.9703 \\
\hline Alcohol & 0.46 & $0.04-4.98$ & 0.5185 & 0.44 & $0.04-4.89$ & 0.4997 \\
\hline Smoking & 0.87 & $0.16-4.58$ & 0.8662 & 0.69 & $0.09-5.67$ & 0.7323 \\
\hline $\mathrm{HTN}^{+}$ & 6.18 & $0.69-55.18$ & 0.1032 & 10.03 & $0.82-123.31$ & 0.0717 \\
\hline DM & 1.17 & $0.21-6.48$ & 0.8602 & 1.17 & $0.17-8.2$ & 0.8761 \\
\hline Tinnitus & 2.50 & $0.41-15.23$ & 0.3203 & 2.58 & $0.42-16.04$ & 0.3092 \\
\hline Ear fullness & 0.13 & $0.02-0.80$ & 0.0280 & 0.10 & $0.01-0.76$ & $0.0262 * *$ \\
\hline $\begin{array}{l}\text { Treatment onset } \\
\text { (days) }\end{array}$ & 1.02 & $0.96-1.09$ & 0.5032 & 1.03 & $0.96-1.11$ & 0.4077 \\
\hline $\begin{array}{l}\text { Recovery time } \\
\text { (months) }\end{array}$ & 1.06 & $0.72-1.56$ & 0.7698 & 1.06 & $0.72-1.57$ & 0.7546 \\
\hline $\begin{array}{l}\text { Hearing level of the } \\
\text { affected ear before } \\
\text { treatment }(\mathrm{dB})\end{array}$ & 1.06 & $1.01-1.11$ & 0.0263 & 1.06 & $1.01-1.12$ & 0.0210 ** \\
\hline $\begin{array}{c}\text { Time to recurrence } \\
\text { (days) }\end{array}$ & 1.02 & $1.00-1.03$ & 0.0442 & 1.02 & 0.99-1.04 & 0.1569 \\
\hline
\end{tabular}

Abbreviation OR; odds ratio; BMI; body mass index; HTN; hypertension; DM; diabetes mellitus. ${ }^{\dagger}$ Logistic regression with Firth's method (reference: patients not experiencing poorer outcomes after recurrence). * Logistic regression of patients with poorer outcomes after the recurrent than after the first episode (reference: patients not experiencing poorer outcomes after recurrence). ${ }^{*}$ Adjusted by age, gender. ${ }^{* *} p<0.05$.

\section{5 studies identified through database search \\ 19 SCOPUS \\ 16 PubMed \\ 0 Cochrane Library}

21 studies excluded

16 duplicates removed

5 language other than English

14 Full-test articles assessed for eligibility

15 studies excluded

1 off topic

4 case reports

9 studies included in qualitative synthesis

Figure 1. PRISMA flow diagram. Abbreviation: PRISMA: Primary Reporting Items for Systematic Review and Meta-analyses. 
Table 5. Studies assessing recurrent ISSNHL.

\begin{tabular}{|c|c|c|c|c|c|c|}
\hline Reference & Country & Study Design & $\begin{array}{l}\text { Number of } \\
\text { Patients with } \\
\text { Recurrence }\end{array}$ & $\begin{array}{l}\text { Recovery Rate } \\
\text { from Recurrence }\end{array}$ & M:F & Conclusions \\
\hline Seo et al. [9] & $\begin{array}{l}\text { South } \\
\text { Korea }\end{array}$ & Retrospective & $\begin{array}{l}\text { First recurrence: } \\
16 \\
\text { Second } \\
\text { recurrence: } 16\end{array}$ & $\begin{array}{c}\text { First recurrence: } \\
78.6 \% \\
\text { Second recurrence: } \\
21.4 \%\end{array}$ & $\begin{array}{l}8: 8 \\
8: 8\end{array}$ & $\begin{array}{l}\text { NLR and PLR higher in patients } \\
\text { with both recurrent and } \\
\text { non-recurrent ISSNHL. }\end{array}$ \\
\hline Park et al. [5] & $\begin{array}{l}\text { South } \\
\text { Korea }\end{array}$ & Retrospective & 11 & $72.7 \%$ & $6: 5$ & $\begin{array}{l}\text { Hearing outcomes were poorer } \\
\text { after a recurrent than after the } \\
\text { first episode, with SSNHL } \\
\text { almost always recurring in the } \\
\text { same ear. }\end{array}$ \\
\hline Ohashi et al. [6] & Japan & Retrospective & 23 & $69.5 \%$ & NA & $\begin{array}{l}\text { Favorable prognostic factors in } \\
\text { patients with recurrent ISSNHL } \\
\text { included an enhanced SP /AP } \\
\text { ratio of ECohG, a low initial AP } \\
\text { threshold, a low initial hearing } \\
\text { level, and an up-sloping type of } \\
\text { audiogram. } \\
\text { Initial vertigo was associated } \\
\text { with unfavorable outcomes in } \\
\text { patients with recurrent ISSNHL. }\end{array}$ \\
\hline Kuo et al. [15] & Taiwan & Retrospective & $\begin{array}{c}\text { Ipsilateral: } 7 \\
\text { Contralateral: } 9\end{array}$ & $\begin{array}{c}50 \% \\
\text { (Ipsilateral type: } \\
71.4 \% \\
\text { Contralateral type: } \\
33.3 \%) \\
\end{array}$ & $\begin{array}{l}3: 4 \\
5: 4\end{array}$ & $\begin{array}{l}\text { Normal VEMPs in the affected } \\
\text { ear of patients with recurrent } \\
\text { sudden deafness may indicate a } \\
\text { good hearing outcome. }\end{array}$ \\
\hline${ }^{\dagger}$ Fushiki et al. [7] & Japan & Retrospective & 33 & $\begin{array}{c}\text { * Recurrence rate } \\
1 \text { year: } 29 \% \\
5 \text { years: } 47 \% \\
\text { (45\% of recurrences } \\
\text { occurred within } 6 \\
\text { months of the first } \\
\text { episode) }\end{array}$ & - & $\begin{array}{l}\text { Recurrence rate higher in } \\
\text { patients with elevated SP / AP } \\
\text { and spontaneous nystagmus } \\
\text { (78.6\%) than in patients with } \\
\text { normal SP/AP and absence of } \\
\text { spontaneous nystagmus }(31.8 \%)\end{array}$ \\
\hline $\begin{array}{c}\text { Furuhashi et al. } \\
\text { [3] }\end{array}$ & Japan & Retrospective & 14 & $78.5 \%$ & $9: 5$ & $\begin{array}{l}\text { Recurrence of sudden deafness } \\
\text { rare during long-term follow-up } \\
\text { The degree of hearing } \\
\text { deterioration on the first } \\
\text { affected side was not } \\
\text { significantly different from that } \\
\text { on the non-affected side }\end{array}$ \\
\hline${ }^{+}$Wu et al. [8] & Taiwan & Retrospective & $\begin{array}{c}2281 \\
\text { (Data from the } \\
\text { Taiwan NHI) }\end{array}$ & $\begin{array}{c}\text { * Recurrence rate } \\
5 \text { years: } 4.99 \%\end{array}$ & $1252: 1029$ & $\begin{array}{l}\text { Factors associated with relapse } \\
\text { included age 35-64 years, } \\
\text { diabetes mellitus, and } \\
\text { hypercholesterolemia }\end{array}$ \\
\hline Pecorari et al. [16] & Italy & Retrospective & 73 & $\begin{array}{c}63 \% \\
\text { * Recurrence rate } \\
2 \text { years: } 5.6 \% \\
5 \text { years: } 10.34 \%\end{array}$ & $30: 43$ & $\begin{array}{l}\text { Recurrence correlated only with } \\
\text { the presence of tinnitus during } \\
\text { follow-up }\end{array}$ \\
\hline Wu et al. [17] & Taiwan & Retrospective & 30 & $\begin{array}{c}43.44 \% \\
\text { (First episode: } \\
53.55 \% \text { ) }\end{array}$ & $16: 14$ & $\begin{array}{l}\text { Hearing recovery after a } \\
\text { recurrent episode correlated } \\
\text { significantly with hearing } \\
\text { outcome after the initial episode. }\end{array}$ \\
\hline
\end{tabular}

Abbreviation: NLR, neutrophil to lymphocyte ratio; PLR, platelet to lymphocyte ratio; ISSNH, idiopathic sudden sensorineural hearing loss; $\mathrm{SP}$, summating potential; AP, action potential; ECohG, electrocochleography; VEMP, vestibular-evoked myogenic potential; NHI, National Health Insurance program * Recurrence rate: cumulative recurrence rate. ${ }^{\dagger}$ These studies only reported about relapse rate.

\section{Discussion}

Many patients who experience recurrent ISSNHL report significant stress relative to the recurrence and are more concerned about recovery than during the first episode of ISSNHL. Clinicians also express concern about the likelihood of recovery relative to the first episode and about the possibility that recurrent ISSNHL is caused by a tumor. 
Most cases of SSNHL are idiopathic; other causes, however, can include vestibular schwannoma, acoustic neuroma, stroke, malignancy, Meniere's disease, trauma, autoimmune disease, syphilis, Lyme disease, and peri-lymphatic fistula [1,18]. The prevalence of vestibular schwannomas in patients with SSNHL has been reported to be $3.0 \%$ [19].

This study assessed 38 patients with recurrent ISSNHL, focusing on the factors associated with recovery. The control group of the present study consisted of patients who did not recover from recurrent ISSNHL. If the process of relapse consists of a series of clinical steps, then the factors among patients who recovered after the first episode may differ between those who did and did not experience poorer recovery after the recurrent episode. ISSNHL is an uncommon disease, and recurrent ISSNHL is very rare; hence, knowledge about the factors associated with patient recovery from recurrent episodes may help in counseling and treating patients.

In general, patients with ISSNHL are advised to start treatment with oral steroids within two weeks [1], and starting treatment after 10 days is a negative prognostic factor [20]. Among patients who experienced recurrent episodes in the present study, those who recovered started their treatment at a mean 5.6 days, whereas those who did not recover started their treatment at a mean 16.7 days, further indicating that delayed treatment was associated with a decreased recovery rate $(p<0.05)$. During the first episode, however, the mean time to treatment onset was similar in patients who did and did not recover (7.2 days vs. 5.5 days). Patients with previous experience of ISSNHL may delay visits to the hospital because they become empirically accustomed to symptoms such as sudden ear fullness, tinnitus, and hearing loss. This may delay the diagnosis and treatment of recurrent ISSNHL. The present findings indicate that patients who experience symptoms of recurrent ISSNHL should seek treatment as soon as possible.

The present study also showed that the ear fullness symptoms and the initial hearing level of the affected ear differed significantly between patients with and without poorer recovery after the recurrent episode than after the first episode of ISSNHL. Recovery of hearing after the first episode was shown to be prognostic for the subsequent hearing outcomes after the recurrent episode [17]. The present study found that the initial hearing loss of the affected ear at the time of recurrence was significantly higher in poorer recovery after the initial episode, as well as being a risk factor for poorer recovery after the recurrent than after the first episode (OR 1.06, 95\% CI 1.01-1.12, $p<0.05$ ) after adjustment for age and sex. Initial profound hearing loss was previously shown to be negatively prognostic for recovery from non-recurrent ISSNHL [20]. Similarly, the present study found that higher initial hearing loss at the time of the recurrent episode was prognostic for poorer recovery after the recurrent than after the first episode.

Ear fullness was experienced by six $(50.0 \%)$ of the twelve patients who experienced poorer recovery after recurrence than after initial ISSNHL and $16(88.9 \%)$ of the 18 patients who did not. Ear fullness is a subjective symptom, expressed as feelings of blockage, plugging, or pressure, that occurs frequently in patients with acute sensorineural hearing loss. For example, the incidence of ear fullness has been reported to be $63.5 \%$ in patients with acute low tone sensorineural hearing loss [18], 40.2\% in patients with ISSNHL [1], and $61.0 \%$ in patients with Meniere's disease [21]. Ear fullness in acute sensorineural hearing loss was not associated with auditory function on audiograms but was associated with the low-frequency region [21]. This association disappeared after the hearing threshold stabilized, and the disappearance of ear fullness has been associated with hearing prognosis. Ear fullness observed in patients with endolymphatic hydrops or Meniere's disease has been associated with a pressure imbalance between the round and oval windows [17,22,23]. Although the mechanisms underlying these associations have not yet been determined, these findings suggest that ear fullness may be due to a functional factor rather than to an anatomical impairment of the cochlea. The mechanism responsible for ear fullness in patients with sensorineural hearing loss needs to be clarified [21,24].

In this study, patients who showed better or similar recovery from the recurrent rather than from the first episode of ISSNHL had more frequent symptoms of ear fullness than 
those who showed poorer recovery from recurrent ISSNHL. Although the ear fullness symptom was associated with the low-frequency region, however, none of the six patients with poorer recovery after the recurrent episode and only four of the sixteen patients without poorer recovery after the recurrent episode who presented with ear fullness showed a low tone loss pattern, indicating that ear fullness symptom is not present only in patients with low tone sudden sensorineural hearing loss. In some respects, patients with poorer recovery after the recurrent episode showed a higher initial hearing loss and more frequent ear fullness symptom at the same time than did patients without poorer recovery after the recurrent episode, suggesting that ear fullness affected the remaining or early stages of loss of hearing function. Taken together, these findings suggest that ear fullness may be prognostic of recovery from recurrent ISSNHL.

ISSNHL has been reported to be associated with a history of hypertension (HTN), chronic kidney disease, diabetes mellitus (DM), hypercholesterolemia, and stroke [25-29]. Analysis of data from the US National Nutrition Survey showed a link between hearing loss and high blood pressure [30]. HTN can cause hemorrhage in the inner ear, reducing capillary blood flow and oxygen supply, and resulting in progressive or sudden sensorineural hearing loss [31]. Moreover, older age and HTN are significant negative prognostic factors for recovery from ISSNHL [20,32]. In the present study, however, HTN was not a statistically significant risk factor for poorer recovery after a recurrent rather than after the first episode of ISSNHL. However, our finding, that HTN was more frequent in patients with poorer recovery after a recurrent than after a first episode, suggests that HTN may be a risk factor for poorer recovery from recurrent ISSNHL. Moreover, acquired and inherited cardiovascular risk factors were found to be associated with an increased risk of developing ISSNHL [33]. The management of cardiovascular diseases, including HTN, is therefore important in preventing the recurrence of ISSNHL.

The rates of DM in patients showing better or similar recovery compared to poorer recovery after a recurrent episode rather than after a first episode were $22.22 \%$ and $25.00 \%$, respectively. Several studies have reported an association between ISSNHL and DM [25-29], although one previous study [34] found no difference in the outer hair cell (OHC) damage, represented by evoked otoacoustic emissions (e-OAEs), between DM patients and healthy subjects in an acute hyperglycemic clamp study which is assumed as a sudden hazardous condition. Sensorineural hearing loss in DM patients has been shown to be associated with longer duration and poor control of DM; however, a higher compromise is observed in DM patients in an acute hyperglycemia condition [34], so it is hard to find the correlation between the acute hyperglycemia condition and ISSNHL. However, it is clear that DM has an effect on hearing loss in the long term, and must be managed appropriately.

The recovery rate of recurrent ISSNHL of our study was $63.2 \%$ and it ranged in between the previous studies in the systematic review (43.4 78.6\%). Similar to our study, hearing outcomes were found to be poorer after the recurrent rather than after the initial episode [5,17]. A previous study reported that $45 \%$ of recurrences occurred within 6 months from the first episode [7]. In comparison, the present study found that the mean times to recurrence were 43.2 days in patients who recovered from the recurrent episode and 44.9 days in those who did not recover. The cumulative relapse rates in studies included in the systematic review ranged from $4.9 \%$ to $47 \%[7,8,16]$.

Those studies found that statistically significant factors associated with recurrence included diabetes mellitus, hypercholesterolemia, and tinnitus. ISSNHL has also been associated with a history of HTN, chronic kidney disease, and stroke. Although the present study found that HTN was not a statistically significant risk factor for recurrent ISSNHL, its prevalence was higher in patients with than without poorer recovery after the recurrent rather than after the first episode of ISSNHL. Both the neutrophil to lymphocyte ratio (NLR) and platelet to lymphocyte ratio (PLR) were found to be higher in patients experiencing both the first and recurrent episodes of ISSNHL than in a normal control group [9]. Similar to our findings, electrocochleography (ECohG) showed that low initial hearing level is prognostic for recovery from ISSNHL [6]. Moreover, a more normal vestibular-evoked myogenic 
potential (VEMP) [15] and better hearing outcome after the initial episode [17] were found to be associated with better hearing outcomes in patients with recurrent ISSNHL.

Although few studies to date have assessed prognosis in patients with recurrent ISSNHL, various clinical, serologic, and audiologic factors have been analyzed. Large population studies have failed to identify factors that are prognostic or predictive of the degree of recovery from recurrent ISSNHL, but in general the factors associated with recurrent ISSNHL have been found not to differ significantly from the factors associated with primary ISNSHL. The present study found that the degree of recovery was associated with treatment onset. A lower initial hearing level and presence of ear fullness symptom were associated with better recovery from the recurrent than from the first episode of ISSNHL. Although further research is needed on the mechanisms responsible for ear fullness, ear fullness can likely be recognized during early stages of functional loss, allowing earlier treatment and improved prognosis.

This study had several limitations. First, this study only analyzed patients who experienced recurrent ISSNHL. To more comprehensively analyze factors prognostic of recurrent ISSNHL, the characteristics of patients who experienced ISSNHL once and those who experienced recurrent ISSNHL should be compared. Second, this study was retrospective in design, which may have introduced a potential selection bias. Third, longer-term serial follow up of patients after recovery from recurrent ISSNHL is needed to specifically classify the patients who might experience additional recurrence. Fourth, a small number of subjects were studied and there was a higher proportion of females compared to males.

\section{Conclusions}

Earlier treatment in patients with recurrent ISSNHL is associated with better hearing outcomes. In addition, ear fullness was associated with a more favorable prognosis, whereas higher initial hearing loss was predictive of a poorer recovery after recurrent than after initial ISSNHL.

Author Contributions: Data curation, S.Y.J.; Formal analysis, S.Y.J.; Writing-original draft, S.Y.J.; Writing-review \& editing, D.W.K., S.H.K., J.Y.B. and S.G.Y. All authors have read and agreed to the published version of the manuscript.

Funding: This research did not receive any specific grant from funding agencies in the public, commercial, or not-for-profit sectors.

Institutional Review Board Statement: This research protocol was approved by the Institutional Review Board of Kyung Hee Medical Center (2019-07-065).

Informed Consent Statement: Not applicable.

Data Availability Statement: The data are available from authors by a reasonable request.

Acknowledgments: This work was supported by the National Research Foundation of Korea (NRF) grant funded by the Korean (NRF 2018R1A6A1A03025124) (NRF 2019R1F1A1049878).

Conflicts of Interest: The authors declare no conflict of interest.

\section{References}

1. Stachler, R.J.; Chandrasekhar, S.S.; Archer, S.M.; Rosenfeld, R.M.; Schwartz, S.R.; Barrs, D.M.; Robertson, P.J. Clinical practice guideline: Sudden hearing loss. Otolaryngol. Head Neck Surg. 2012, 146, S1-S35. [CrossRef]

2. Byl, F.M., Jr. Sudden hearing loss: Eight years' experience and suggested prognostic table. Laryngoscope 1984, $94,647-661$. [CrossRef] [PubMed]

3. Furuhashi, A.; Matsuda, K.; Asahi, K.; Nakashima, T. Sudden deafness: Long-term follow-up and recurrence. Clin. Otolaryngol. 2002, 27, 458-463. [CrossRef] [PubMed]

4. Psifidis, A.D.; Psillas, G.K.; Daniilidis, J.C. Sudden sensorineural hearing loss: Long-term follow-up results. Otolaryngol. Head Neck Surg. 2006, 134, 809-815. [CrossRef] [PubMed]

5. Park, I.S.; Kim, Y.B.; Choi, S.H.; Hon, S.M. Clinical analysis of recurrent sudden sensorineural hearing loss. ORL 2013, 75, 245-249. [CrossRef] 
6. Ohashi, T.; Nishino, H.; Arai, Y.; Nishimoto, Y.; Kakutani, T.; Koizuka, I. Electrocochleographic findings in recurrent idiopathic sudden sensorineural hearing loss. Acta Otolaryngol. 2012, 132, 1022-1027. [CrossRef]

7. Fushiki, H.; Junicho, M.; Aso, S.; Watanabe, Y. Recurrence rate of idiopathic sudden low-tone sensorineural hearing loss without vertigo: A long-term follow-up study. Otol. Neurotol. 2009, 30, 295-298. [CrossRef]

8. Wu, C.M.; Lee, K.J.; Chang, S.L.; Weng, S.F.; Lin, Y.S. Recurrence of idiopathic sudden sensorineural hearing loss: A retrospective cohort study. Otol. Neurotol. 2014, 35, 1736-1741. [CrossRef]

9. Seo, Y.J.; Park, Y.A.; Bong, J.P.; Park, D.J.; Park, S.Y. Predictive value of neutrophil to lymphocyte ratio in first-time and recurrent idiopathic sudden sensorineural hearing loss. Auris Nasus Larynx. 2015, 42, 438-442. [CrossRef]

10. Hughes, F.B.; Freedman, M.A.; Haberkamp, T.J.; Guay, M.E. Sudden sensorineural hearing loss. Otolryngol. Clin. N. Am. 1996, 29, 393-405. [CrossRef]

11. Cvorovic, L.; Deric, D.; Probst, R.; Hegemann, S. Prognostic model for predicting hearing recovery in idiopathic sudden sensorineural hearing loss. Otol. Neurotol. 2008, 29, 464-469. [CrossRef] [PubMed]

12. Mattox, D.E.; Lyles, C.A. Idiopathic sudden sensorineural hearing loss. Am. J. Otol. 1989, 10, 242-247. [PubMed]

13. Siegel, L.G. The treatment of idiopathic sudden sensorineural hearing loss. Otolaryngol. Clin. N. Am. 1975, 8, 467-473. [CrossRef]

14. Liberati, A.; Altman, D.G.; Tetzlaff, J.; Mulrow, C.; Gøtzsche, P.C.; Ioannidis, J.P.; Moher, D. The PRISMA statement for reporting systematic reviews and meta-analyses of studies that evaluate health care interventions: Explanation and elaboration. J. Clin. Epidemiol. 2009, 62, e1-e34. [CrossRef]

15. Kuo, Y.L.; Young, Y.H. Hearing outcome of recurrent sudden deafness: Ipsilateral versus contralateral types. Acta Otolaryngol. 2012, 132, 247-254. [CrossRef]

16. Pecorari, G.; Riva, G.; Bruno, G.; Naqe, N.; Nardo, M.; Albera, A.; Albera, R. Recurrences in Sudden Sensorineural Hearing Loss: A Long-Term Observational Study. Am. J. Audiol. 2020, 29, 18-22. [CrossRef]

17. Wu, P.H.; Lee, C.Y.; Chen, H.C.; Lee, J.C.; Chu, Y.H.; Cheng, L.H.; Shih, C.P. Clinical characteristics and correlation between hearing outcomes after different episodes of recurrent idiopathic sudden sensorineural hearing loss. Auris Nasus Larynx. 2021, 48, 870-877. [CrossRef]

18. Rauch, S.D. Clinical practice. Idiopathic sudden sensorineural hearing loss. N. Engl. J. Med. 2008, 359, 833-840. [CrossRef]

19. Fujita, T.; Saito, K.; Kashiwagi, N.; Sato, M.; Seo, T.; Doi, K. The prevalence of vestibular schwannoma among patients treated as sudden sensorineural hearing loss. Auris Nasus Larynx. 2019, 26, 78-82. [CrossRef]

20. Edizer, D.T.; Çelebi, Ö.; Hamit, B.; Baki, A.; Yiğit, Ö. Recovery of idiopathic sudden sensorineural hearing loss. J. Int. Adv. Otol. 2015, 11, 122-126. [CrossRef]

21. Sakata, T.; Esaki, Y.; Yamano, T.; Sueta, N.; Nakagawa, T. A comparison between the feeling of ear fullness and tinnitus in acute sensorineural hearing loss. Int. J. Audiol. 2008, 47, 134-140. [CrossRef] [PubMed]

22. Gorga, M.P.; Kaminski, J.R.; Beauchaine, K.L. Effects of stimulus phase on the latency of the auditory brainstem response. J. Am. Acad. Audiol. 1991, 2, 1-6. [PubMed]

23. Tonndorf, J.; Tabor, J.R. Closure of th cochlear windows: Its effect upon air- and bone-conduction. Ann. Otol. Rhinol. Laryngol. 1962, 71, 5-29. [CrossRef] [PubMed]

24. Sakata, T.; Kato, T. Feeling of ear fullness in acute sensorineural hearing loss. Acta Oto-Laryngol. 2006, 126, 828-833. [CrossRef] [PubMed]

25. Chang, S.L.; Hsieh, C.C.; Tseng, K.S.; Weng, S.F.; Lin, Y.S. Hypercholesterolemia is correlated with an increased risk of idiopathic sudden sensorineural hearing loss: A historical prospective cohort study. Ear Hear. 2014, 35, 256-261. [CrossRef] [PubMed]

26. Lin, C.; Lin, S.W.; Lin, Y.S.; Weng, S.F.; Lee, T.M. Sudden sensorineural hearing loss is correlated with an increased risk of acute myocardial infarction: A population-based cohort study. Laryngoscope 2013, 123, 2254-2258. [CrossRef] [PubMed]

27. Lin, S.W.; Lin, Y.S.; Weng, S.F.; Chou, C.W. Risk of developing sudden sensorineural hearing loss in diabetic patients: A population-based cohort study. Otol. Neurotol. 2012, 33, 1482-1488. [CrossRef]

28. Lin, C.; Hsu, H.T.; Lin, Y.S.; Weng, S.F. Increased risk of getting sudden sensorineural hearing loss in patients with chronic kidney disease: A population-based cohort study. Laryngoscope 2013, 123, 767-773. [CrossRef]

29. Lin, H.C.; Chao, P.Z.; Lee, H.C. Sudden sensorineural hearing loss increases the risk of stroke: A 5-year follow-up study. Stroke 2008, 39, 2744-2748. [CrossRef]

30. Agrawal, Y.; Platz, E.A.; Niparko, J.K. Prevalence of hearing loss and differences by demographic characteristics among US adults: Data from the National Health and Nutrition Examination Survey, 1999-2004. Arch Intern. Med. 2008, 168, 1522-1530. [CrossRef]

31. Siegelaub, A.B.; Friedman, G.D.; Adour, K.; Seltzer, C.C. Hearing loss in adults: Relation to age, sex, exposure to loud noise, and cigarette smoking. Arch Environ. Occup. Health 1974, 29, 107-109. [CrossRef] [PubMed]

32. Lionello, M.; Staffieri, C.; Breda, S.; Turato, C.; Giacomelli, L.; Magnavita, P.; Marioni, G. Uni-and multivariate models for investigating potential prognostic factors in idiopathic sudden sensorineural hearing loss. Eur. Arch. Otorhinol. 2015, 272, 1899-1906. [CrossRef] [PubMed]

33. Lin, R.J.; Krall, R.; Westerberg, B.D.; Chadha, N.K.; Chau, J.K. Systematic review and meta-analysis of the risk factors for sudden sensorineural hearing loss in adults. Laryngoscope 2012, 122, 624-635. [CrossRef] [PubMed]

34. Sasso, F.C.; Salvatore, T.; Tranchino, G.; Cozzolino, D.; Caruso, A.A.; Persico, M.; Torella, R. Cochlear Dysfunction in Type 2 Diabetes: A complication Independent of Neuropathy and Acute Hyperglycemia. Metabolism 1999, 48, 1346-1350. [CrossRef] 